\title{
GÊNERO E SAÚDE: um olhar para a mulher estomizada no contexto social e familiar
}

DOI: 10.22289/2446-922X.V7N1A27

\author{
Sirlei Favero Cetolin ${ }^{1}$ \\ Simone Kelly Cetolin Wackerhagen \\ Vilma Beltrame \\ Jorge Fernando Soares
}

\section{RESUMO}

Este artigo apresenta resultados de uma pesquisa qualitativa, realizada com o objetivo de identificar aspectos de superação no convívio familiar e social de mulheres estomizadas. As informações foram coletadas através de uma entrevista em momentos da retirada mensal das bolsas coletoras e acessórios, fornecidos pelo Sistema Único de Saúde (SUS), no decorrer do ano de 2019. Participaram do estudo, mulheres estomizadas residentes em municípios de abrangência da $1^{\underline{a}}$ Gerência Regional de Saúde do Estado de Santa Catarina. Dentre os resultados, percebeu-se que a convivência com a estomia provocou mudanças significativas relacionadas as relações afetivas e amorosas das mulheres. A insegurança e o medo da rejeição familiar e social, foram destacadas como principais geradoras de sentimentos negativos. Esses sentimentos também se evidenciaram nas relações de gênero, por conta da construção histórica voltada para à importância da aparência para o sexo feminino. Em contrapartida, a adequação à condição de estomizadas foi demonstrada por relatos contundentes de resgate da autoestima e "opção pela vida". Realizar o estudo possibilitou importantes reflexões, dentre as quais, a responsabilidade dos profissionais da saúde, em contribuir para que todo o processo que envolve a condição de estomizada, seja amenizado e humanizado.

Palavras-Chave: Estomia; Saúde da Mulher; Gênero e Saúde; Saúde Mental.

\section{GENDER AND HEALTH: a look at the stomeed woman in the social and family context}

\section{ABSTRACT}

This article presents results of a qualitative research, carried out with the objective of identifying aspects of overcoming in the family and social life of ostomized women. The information was collected through an interview during the monthly withdrawal of collection bags and accessories, provided by the Unified Health System (SUS), during 2019. Participated in the study, ostomized women living in municipalities covered by the 1st Management Regional Health Department of the State of Santa Catarina. Among the results, it was noticed that living with the ostomy caused significant changes related to the affective and loving relationships of women. Insecurity and fear of family and social rejection were highlighted as the main generators of negative feelings. These feelings were also evident in gender relations, due to the historical construction focused on the

${ }^{1}$ Endereço eletrônico de contato: sirleicetolin@gmail.com

Recebido em 15/01/2021. Aprovado pelo conselho editorial para publicação em 22/06/2021.

Rev. Psicol Saúde e Debate. Jun., 2021:7(1): 398-407. 
importance of appearance for the female sex. On the other hand, the adequacy to the condition of ostomized women was demonstrated by strong reports of the recovery of self-esteem and "option for life". Carrying out the study enabled important reflections, among which, the responsibility of health professionals, to contribute so that the whole process that involves the condition of ostomy, is reduced and humanized.

Key words: Ostomy; Women's Health; Gender and Health; Mental health.

\section{GÉNERO Y SALUD: una mirada a la mujer estimada en el contexto social y familiar}

\section{RESUMEN}

Este artículo presenta los resultados de una investigación cualitativa, realizada con el objetivo de identificar aspectos de superación en la vida familiar y social de las mujeres ostomizadas. La información fue recolectada a través de una entrevista durante el retiro mensual de bolsas de recolección y accesorios, brindado por el Sistema Único de Salud (SUS), durante el 2019. Participaron del estudio, mujeres ostomizadas residentes en municipios cubiertos por la 1a Gestión Departamento Regional de Salud del Estado de Santa Catarina. Entre los resultados, se notó que convivir con la ostomía provocó cambios significativos relacionados con las relaciones afectivas y amorosas de las mujeres. Se destacaron la inseguridad y el miedo al rechazo familiar y social como los principales generadores de sentimientos negativos. Estos sentimientos también se evidenciaron en las relaciones de género, debido a la construcción histórica centrada en la importancia de la apariencia para el sexo femenino. Por otro lado, la adecuación a la condición de las mujeres ostomizadas quedó demostrada por fuertes informes de recuperación de la autoestima y "opción por la vida". La realización del estudio permitió reflexiones importantes, entre las que destaca la responsabilidad de los profesionales de la salud, para contribuir a que todo el proceso que involucra la condición de ostomía, sea reducido y humanizado.

Palabras clave: Ostomía; La Salud de la Mujer; Género y Salud; Salud Mental.

\section{INTRODUÇÃO}

A abordagem empreendida, neste artigo, contextualiza informações sobre as relações de gênero, no contexto de mulheres que foram submetidas a cirurgias e, encontram-se estomizadas.

A pessoa estomizada é aquela submetida a uma cirurgia que resulta na confecção de um estoma, que é uma comunicação artificial entre os órgãos ou vísceras, até o meio externo, para drenagens, eliminações ou nutrição (Sampaio, Aquino, Araújo, \& Galvão, 2008). Os estomas mais comuns são os intestinais e urinários, classificados em três tipos, de acordo com o local afetado: ileostomia, colostomia e urostomia (Gardiner, 2013).

Os urinários, denominados de derivações urinárias, são realizados em pacientes com doenças que envolvem a pelve renal, ureteres, bexiga e uretra, e tem por objetivo preservar a função renal. Os estomas intestinais são indicados quando alguma parte do intestino apresenta disfunção, obstrução ou lesão (Recalla, English, Nazari, Mayo, Miller, \& Gray, 2013).

Rev. Psicol Saúde e Debate. Jun., 2021:7(1): 398-407. 
A pessoa estomizada tem sua perspectiva de vida alterada e pode encontrar inúmeras dificuldades de adaptação e/ou adequação à sua condição, como a autoimagem; o autocuidado; formas de lazer; atenção ao estoma e a bolsa coletora; eliminação dos odores; restrição alimentar; convívio social e nas relações afetivas e amorosas (Nascimento, Trindade, Luz, \& Santiago, 2011).

Os sentimentos despertados nas pessoas pela nova condição, geralmente num primeiro momento, são de frustração e incapacidade e, podem provocar isolamento social (Cascais, Martini, \& Almeida, 2007). Quando a situação é vivenciada pela mulher, os sentimentos acabam sendo ainda mais intensos, pelo fato de que a imagem corporal está intimamente ligada ao aspecto do feminino, em que, a identidade e autoestima estão amplamente marcadas pela subjetividade construída socialmente, permeada por conteúdos que definem as representações sociais de gênero.

Por meio do conceito histórico de gênero é possível compreender que ser mulher ou ser homem é resultado de uma construção social, que estabelece o papel que cabe a cada um nas relações sociais (Feijó \& Macedo, 2012). O conceito de gênero não se resume a uma categoria de análise, mas a uma categoria histórica que remete a construção social do masculino e do feminino (Saffioti, 2004).

E neste aspecto, a estomia obriga a mulher a realizar grandes transformações pessoais. Apesar de manter sua condição encoberta sob as roupas, rompe com os seus esquemas anteriores e pode levar a mulher sentir-se diferente das pessoas com quem convive. O impacto da presença da estomia determina uma alteração da imagem corporal que possibilita o aparecimento de diversas reações e sentimentos a partir de sua realidade, principalmente, porque em função do ato cirúrgico, ocorre a perda da capacidade natural de eliminação das fezes e/ou urina, exigindo a utilização de equipamentos desconhecidos anteriormente, como é o caso da bolsa coletora ou também chamada bolsa de colostomia.

O processo de adaptação ocorre com o ajuste de toda uma vida, em um novo contexto, em que fatores importantes têm, muitas vezes, que ser abandonados, substituídos ou reduzidos (Menezes \& Quintana, 2008).

O abalo na autoestima e no auto conceito, resultantes da alteração da sua imagem corporal, infelizmente, são esperados, assim como, a perda do status social devido ao isolamento inicial, muitas vezes imposto pela própria pessoa estomizada. Podem surgir também sentimentos de inutilidade, pois é comum encontrar pacientes que, em um primeiro momento, nutrem a fantasia de que perderão a capacidade produtiva, levando-os a exteriorizar sentimentos como desgosto, ódio, repulsa e medo, bem como, importantes alterações sócio familiares (Barbutti, Silva, \& Abreu, 2008). 


\section{MATERIAIS E MÉTODOS}

Trata-se de uma pesquisa qualitativa com base em informações coletadas na ocasião da retirada mensal das bolsas coletoras e acessórios fornecidos pelo Sistema Único de Saúde (SUS) no Setor de Estomizados de uma Gerência Regional de Saúde no interior do Estado de Santa Catarina no decorrer do ano de 2019.

A abordagem qualitativa foi escolhida por trabalhar com um universo de significados, motivos, aspirações, crenças, valores e atitudes, correspondendo à profundidade das relações sociais (Minayo, 2006).

Para a coleta de dados utilizou-se de uma entrevista semiestruturada, pois esta permite caracterizar a subjetividade e a particularidade dos discursos. Posteriormente, a conversa mantida na entrevista, houve a categorização das falas e a pesquisa foi aprofundada e embasada a partir da literatura pertinente ao assunto.

Segundo Bardin (2016) a categorização é uma operação de classificação de elementos constitutivos de um conjunto, por diferenciação e, seguidamente, por agrupamento, com critérios previamente definidos. Foram analisadas as categorias: Gênero e condição de estomizada.

O projeto foi submetido ao Comitê de Ética em Pesquisa (CEP) e aprovado sob o Parecer № 2.277.238. As participantes foram identificadas, ao longo do artigo, com letras do alfabeto, para garantia do anonimato quanto à identidade das mesmas.

\section{RESULTADOS E DISCUSSÃO}

Encontravam-se cadastradas no local, 42 pessoas com estomia intestinal definitiva, residentes em 05 municípios de âmbito de atuação da Gerência Regional de Saúde, dentre as quais 20 homens e 22 mulheres. Contudo, existem situações em que são os familiares que fazem a retirada dos materiais no local e, portanto, não foi possível realizar a pesquisa com o universo de mulheres cadastradas. A amostragem participante, foi de 15 mulheres que aceitaram fazer parte do estudo, correspondendo a $72,6 \%$ do universo. Todavia, a partir dos registros existentes no setor, foi possível constatar que dentre as 22 mulheres, 14 eram casadas, 5 viúvas e 3 separadas. Todas as mulheres haviam sido submetidas à cirurgia para tratamento do câncer de intestino. Referente às idades, 2 possuíam mais de 81 anos, 7 entre 71 e 80 anos, 6 entre 61 e 70 anos, 6 entre 51 e 60 anos e uma menos de 30 aos de idade. Quanto ao tempo decorrente, desde que realizaram a cirurgia de estomia intestinal definitiva e fazem uso das bolsas de colostomia, 5 mulheres haviam realizado a cirurgia há menos de dois anos, 4 entre três e cinco anos, 5 entre seis e oito anos, 3 entre nove e doze anos e 5 realizaram há mais de 15 anos.

Rev. Psicol Saúde e Debate. Jun., 2021:7(1): 398-407. 
Relações de Gênero

Relações de Gênero são uma categoria que foi naturalizada e construída historicamente a partir das relações sociais estabelecidas. Vale lembrar que, assuntos relacionados às relações de gênero têm se apresentado com espaço privilegiado para investigações científicas em todo o Brasil, principalmente, num momento em que as problemáticas inclusas à temática necessitam ser enfrentadas com políticas e legislação específicas. As participantes do estudo, foram questionadas quanto ao fato de serem mulheres e possuírem um estoma. Houve diferentes manifestações dentre as quais, destacaram-se as seguintes:

"Eu sinto que por ser mulher é mais complicado por causa do uso da bolsa, me sinto desconfortável, não é todo tipo de roupa que posso usar e que fica bem" (A).

Estava de casamento marcado quando fiz a cirurgia e o relacionamento acabou meu noivo não aceitou casar com uma estomizada. O tempo passou, conheci outra pessoa e nos casamos, hoje está tudo bem. Mas, foi bem complicado, percebi que se eu fosse o homem não teria feito essa diferença que ele fez. (D).

Para o homem que não é cobrada a aparência na sociedade, ele pode ter barriga, não ter cabelo, não se cuidar e não tem problemas, mas para a mulher a mudança acho que é maior em todos os aspectos da vida. (E).

É difícil tanto para mulher quanto para o homem, mas a gente acaba tendo que se acostumar com essa nova condição. Como mulher acho que é mais difícil ainda, porque a gente quer estar bonita, limpa sempre e, como tudo é meio incontrolável, as vezes complica. (N).

As representações sociais implicam na imagem da mulher com um corpo ideal, sinônimo de juventude, beleza, vigor e saúde. O corpo normal e aceito socialmente é aquele produtivo e saudável. 'O belo é bom e o feio é mau'. A mídia perpetua a chamada 'obsessão pela aparência' que a própria sociedade construiu e torna-se, numa versão atual dos mitos clássicos, o 'espelho mágico que reflete o mundo idealizado' (Rocha, 1991; Salter, 1992; Freedmann, 1994).

"Imagina que tipo de mulher eu me sentia, sempre com desconforto, parecia que não era mais o meu corpo". (B).

Eu vejo que tem muita diferença entre o homem e a mulher, principalmente porque as mulheres logo assumem o cuidado com seu corpo e com a bolsa. Vejo que quando é o marido que é estomizado a mulher dele tem que auxiliar no cuidado e na higiene. Parece que a gente tem que cuidar do outro. Mas, eu me viro sozinha. $(\mathrm{G})$

"No começo meu marido não gostou muito de que a minha estomia seria definitiva, isso me deixava triste. Com o tempo ele não reclama mais. Faz tanto tempo que uso que ele se acostumou e eu também". (M).

Rev. Psicol Saúde e Debate. Jun., 2021:7(1): 398-407. 
A vivência da dor ou do desconforto surge no local onde o "ter" um corpo evolui para o "ser" um corpo (Novaes, 1975). A mulher estomizada vê-se diante de modificações em sua fisiologia, surgindo também à necessidade de cuidados com a bolsa de colostomia. Sentimentos variados emergem, incluindo conflitos, preocupações e dificuldades diante das limitações impostas no cotidiano. Ser-corpo é constituinte do existir, sendo a corporeidade um caráter fundamental do ser humano, inseparável dele e integrante de suas relações com o mundo.

\section{Condição de Estomizada}

O uso da bolsa de colostomia pode ser considerado como uma nova forma de se relacionar com o mundo, no espaço e tempo vivenciados, em que as pacientes percebem outra concepção de corpo. Neste sentido, a forma de se perceber pode transcender ao biológico e ser percebida também como emocional, social, familiar, cultural, espiritual dentre outros aspectos e dimensões do ser humano.

"Penso que a questão é principalmente de como a gente se enxerga, nunca havia pensado em viver essa situação de estomizada aí apareceu o câncer e tive que vivê-la". (F).

São situações que a vida nos coloca. Tive que fazer quimioterapia e depois inúmeros exames que nem sabia que existiam. Tudo isso foi me fortalecendo como pessoa, hoje o fato de ser estomizada é a minha condição de vida. E eu quero viver. $(\mathrm{H})$.

A experiência de ter uma estomia por câncer conduz as pessoas a viverem situações que fogem às normas culturais e afetam os significados que elas dão a si mesmas, à doença, ao tratamento e à própria existência. No contexto do adoecimento, visualizam-se dois significados culturais importantes: o câncer - doença que carrega o estigma da morte e do sofrimento -, e a ostomia, mutilação física que, apesar de ser oculta, traz consigo inúmeras consequências (Maruyama, 2004).

Há mais de 30 anos eu tive que tomar uma decisão. Era viver ou morrer. Decidi viver. Por isso consegui acompanhar meus filhos, ver meus netos crescer e hoje brinco com os bisnetos. Penso que valeu a pena a minha decisão. (I).

Fui para a cirurgia e ninguém me falou o que iria acontecer depois, quando acordei estava com a bolsinha, pensei que era algo que depois iria ser retirado, mas ficou. Não foi nada fácil me enxergar dessa forma. Perceber que minhas fezes ficavam expostas e que não consigo controla-las não é uma condição agradável, mas a gente vai superando e percebendo que somos muito mais do que isso tudo $(\mathrm{J})$.

Então, foi uma caminhada longa até aceitar que a ostomia faria parte do resto dos meus dias. Como mulher acho que foi ainda pior a aceitação das pessoas, mas eu me resolvi. Tive que mudar muitas coisas, mas, considero que tenho uma vida normal, saio de casa, passeio e não me preocupo mais tanto. A fé em Deus me ajuda a superar cada dia mais a minha condição. $E$ isso. (L).

Rev. Psicol Saúde e Debate. Jun., 2021:7(1): 398-407. 
Pode-se perceber que a adaptação ocorre com o ajuste de toda uma vida, em um novo contexto, em que fatores antes importantes, necessitam serem abandonados, substituídos ou reduzidos. É um processo único, individual e intransferível que vai se desenvolvendo com o passar do tempo e envolve uma série de questões, dentre as quais a aceitação da "nova" condição de vida.

Com a estomia ficou mais complicado a relação de casal. Muitas vezes me sinto bem constrangida, principalmente pela questão do odor que às vezes por mais que a gente cuide acaba ocorrendo. Os gases também provocam uma situação nada agradável. Hoje já tem várias opções para a higiene, bem diferente de quando fiz a cirurgia, então a gente vai se adequando (B).

Agora como passou bastante tempo desde que foi feita a cirurgia já me adaptei, mas sentia muita insegurança, dúvidas e medo que meu marido fosse me abandonar. Muitas vezes me afastei por dias dele, não queria nem que chegasse perto de mim. (C).

Passado o choque inicial e depois de um período de adaptação, a maioria dos pacientes pode levar uma vida normal, devendo sempre respeitar alguns pontos fundamentais de higiene, e utilizar materiais adequados sob orientação médica para conseguirem a segurança que necessitam (Barbutti, Silva, \& Abreu, 2008).

A minha vida mudou literalmente, meu marido arrumou outra mulher e se separou de mim. Foi um período muito difícil de muita tristeza. Mas, com o tempo eu aprendi a conviver comigo mesma e com a minha condição de estomizada. Me afastei do trabalho, hoje procuro viajar, visitar os filhos e viver a vida da melhor forma que posso. (E)

Passei por um período de muito medo de sair de casa, parecia que a todo o momento a bolsa poderia vazar e eu ficar numa situação constrangedora em público. As poucas vezes que saía ficava rezando para não acontecer nada desagradável (O).

"Eu me preocupava demais com o fato de as pessoas perceberem que sou estomizada. Fiquei muito tempo sem sair de casa, não ia para a igreja, para a comunidade. Tudo me fazia sentir vergonha e constrangimento" $(P)$.

Além dos problemas comumente enfrentados pelos pacientes que são submetidos a uma cirurgia, os estomizados enfrentam outros, tais como a exposição a uma série de constrangimentos sociais, pela possibilidade de saída dos gases e vazamento de excrementos mediante a inexistência de controle voluntário, o que provoca o medo nos relacionamentos afetivos e/ou amorosos e na exposição em público. Normalmente tais problemas podem ser compreendidos sob as dimensões física, psicológica, social e espiritual (Gemelli \& Zago, 2002).

Sentimentos de incapacidade e desprestígio podem afetar as relações sociais e familiares das pessoas estomizadas, podem ocorrer mudanças na vida sexual, relacionadas com a alteração da imagem do corpo e a consequente diminuição da autoestima, bem como na preocupação relacionada com a eliminação de odores e fezes durante a relação sexual, pois não há o controle 
sobre as eliminações fecais, sobre o barulho provocado, além do uso da bolsa coletora ser constante, e visualmente não ser atraente (Brasil, 2000).

A reabilitação do estomizado visa restituir-lhe as atividades do convívio social e melhorar a qualidade de vida diante do impacto da aquisição do estoma. A primeira etapa desse processo deve ser a aceitação do estoma pela pessoa, entendendo que este, foi confeccionado com o intuito de preservar sua saúde e vida. A partir daí, os cuidados com higiene e alimentação podem assegurar melhoria qualidade da vida diária, assim como algum tipo de controle sobre as consequências da ostomia (Barbutti, Silva, \& Abreu, 2008).

\section{CONSIDERAÇÕES FINAIS}

$\mathrm{Na}$ convivência com a ostomia as mudanças mais comuns estão relacionadas à dificuldade inicial do retorno ao convívio social e as relações afetivas e amorosas. A insegurança e o medo da rejeição têm sido destacados como principais geradores de sentimentos negativos. Nas relações de gênero a condição da mulher tem provocado sentimentos de dor e constrangimento, principalmente, por conta da construção histórica voltada à aparência do feminino. Contudo, a adequação a nova condição tem sido de superação com relatos de "opção pela vida". A reinserção social e familiar tem contribuído para o resgate da autoestima das mulheres. Também referente ao cuidado do outro, em que geralmente a mulher possui o papel de cuidadora, as participantes expressaram que a partir da estomia o cuidado foi incorporado por elas próprias, se dizendo cuidadoras de si mesmas. Concluindo, gênero é uma categoria de análise útil para intervenções profissionais com mulheres que vivenciam o processo de estomia definitiva, pois, possibilita compreender melhor, as relações entre homens e mulheres com base na equidade e, acima de tudo, no respeito às diferenças. O propósito deste artigo foi apresentar uma linha de pensamento que discute as relações de gênero que de fato estruturam as relações sociais estabelecidas ao longo dos tempos. Foram 15 mulheres que demonstraram uma força incomum de superação, realizar o estudo possibilitou inúmeras reflexões, dentre as quais, a nossa responsabilidade como profissionais da saúde, em contribuir para que todo o processo que envolve a superação, seja amenizado e humanizado.

Rev. Psicol Saúde e Debate. Jun., 2021:7(1): 398-407. 


\section{REFERÊNCIAS}

Barbutti, R. C. S., Silva, M. C. P., \& Abreu, M. A. L. (2008). Ostomia, uma difícil adaptação [Versão Eletrônica]. Revista SBPH, 11(2), 27-39. Retirado em 30 dezembro, 2020, em http://pepsic.bvsalud.org/scielo.php?script=sci arttext\&pid=S151608582008000200004.

Bardin, L. (2016). Análise de Conteúdo. Portugal: 70 Edições.

Brasil, Departamento de Psiquiatria - UNIFESP/RPM. (2000). Correlação entre adaptação psicossocial à colostomia permanente e resposta psicológica ao câncer. Retirado em 22 novembro, 2018, em www.uniesp.br

Cascais, A. F. M. V., Martini, J. G., \& Almeida, P. J. dos S. (2007, março). O impacto da ostomia no processo de viver humano. Texto contexto - enferm., 16(1), 163-167. Retirado em 30 dezembro, 2020, em http://www.scielo.br/scielo.php?script=sci arttext\&pid=S0104$\underline{07072007000100021 \& \operatorname{lng}=e n}$. http://dx.doi.org/10.1590/S0104-07072007000100021.

Feijó, M. R., Macedo, R. M. (2012). Gênero, cultura e rede social - a construção social da desigualdade por meio da linguagem. Nova Perspectiva Sistêmica, (44), 21-34.

Freedman, R. (1994). Meu corpo... meu espelho: aprendendo a conviver com seu corpo, a aceitar seu visual e a gostar cada vez mais de você. Rio de Janeiro: Rosa dos Tempos.

Gardiner, A. (2013). Addressing common stoma complications. Nurs resident care, 15(3), 128. $\begin{array}{lllll}\text { Retirado em } & 17 & \text { setembro, } & 2019, & \text { em }\end{array}$ http://www.magonlinelibrary.com/doi/abs/10.12968/nrec.2013.15.3.128.

Gemelli, L. M. G., \& Zago, M. M. F. (2002). A interpretação do cuidado com o ostomizado na visão do enfermeiro: um estudo de caso. Revista Latino-am. Enferm., 10(1), 34-40.

Maruyama, S. (2004). A experiência da colostomia por câncer como ruptura biográfica na visão dos portadores, familiares e profissionais de saúde: um estudo etnográfico. Tese de doutorado, Programa de Pós-Graduação em Enfermagem Fundamental, Escola de Enfermagem de Ribeirão Preto - Universidade de São Paulo, Ribeirão Preto, SP, Brasil.

Menezes, A. P. S., \& Quintana, J. F. A. (2008, fevereiro). Percepção do indivíduo estomizado quanto à sua situação. Rev. Bras. Prom. Saúde, 21(1), 13-8.

Minayo, M. C. S. (2006). Pesquisa qualitativa em saúde - Desafio do Conhecimento. Rio de Janeiro: Vozes.

Nascimento, C. de M. de S., Trindade, G. L. B., Luz, M. H. B. A., \& Santiago, R. F. (2011). Vivência do paciente estomizado: uma contribuição para a assistência de enfermagem. Texto \& Contexto - Enfermagem, 20(3), 557-564. De https://dx.doi.org/10.1590/S0104-07072011000300018.

Novaes, M. H. (1975). Deficiência física: imagem corporal e autoconceito. In Novaes, M. H Psicologia aplicada à reabilitação (pp. 33-8). Rio de Janeiro: Imago.

Recalla, S. I., English, K., Nazarali, R., Mayo, S., Miller, D., Gray, M. (2013, set./out.). Ostomy care and management: a systematic review. J Wound Ostomy Continence Nurs. 40(5), 489-500

Rev. Psicol Saúde e Debate. Jun., 2021:7(1): 398-407. 
Rocha, E. F. (1991). Corpo deficiente: em busca da reabilitação? Uma reflexão a partir da ética das pessoas portadoras de deficiência física. Dissertação de mestrado, Instituto de Psicologia, Universidade de São Paulo, São Paulo, Brasil.

Saffioti, H. I. B. (2004). Gênero, patriarcado, violência. São Paulo: Fundação Perseu Abramo.

Salter, M. J. (1992). Aspects of sexuality for patients with stomas and continent pouches. J. ET Nurs. 19(4), 126-30.

Sampaio, F. A. A., Aquino, P. S., Araújo, T. L., \& Galvão. M. T. G. (2008). Nursing care to an ostomy patient: application of the Orem's theory. Acta Paul Enferm, 21(1), 94-100. Retirado em 11 fevereiro, 2021, em http://dx.doi.org/10.1590/S0103-21002008000100015. 